\title{
Antimony Speciation in Spirits Stored in PET Bottles: Identification of a Novel Antimony Complex
}

Received 00th January 20xx, Accepted 00th January 20xx

DOI: $10.1039 / x 0 x \times 00000 x$

www.rsc.org/

\author{
S. Carneado a , J.F. López-Sánchez ${ }^{a}$, A. Sahuquillo ${ }^{a}$, E. Klontzas ${ }^{b}$, G. E. Froudakis ${ }^{b}$, S.A. Pergantis ${ }^{\text {b,c, }}{ }^{*}$
}

Total antimony and its $+\mathrm{V}$ and $+\mathrm{III}$ oxidation state species were determined in twelve spirit samples (Greek raki and tsipouro) stored in polyethylene terephthalate bottles. Reliable and reproducible results were obtained following direct analysis by using ICP-MS providing total Sb concentrations between $0.4-4 \mu \mathrm{L} \mathrm{L}^{-1}$. Antimony speciation analysis by LC-ICP-MS was also assessed, showing the presence of both inorganic Sb species along with an unknown Sb complex, which was the predominant species in all samples analysed. The structure of this complex was investigated by using liquid chromatography with highresolution tandem mass spectrometry. The analysis gave evidence for an acetaldehyde-bisulphite pyruvate Sb complex with the formula: $\mathrm{C}_{7} \mathrm{H}_{14} \mathrm{O}_{12} \mathrm{~S}_{2} \mathrm{Sb}$. The proposed ligands are organic substances expected to be present in the raki matrix. In addition, the influence of high temperature storage conditions and extended exposure times up to two weeks, on $\mathrm{Sb}$ migration from PET bottles into raki samples was investigated. Total Sb and Sb species content was determined by ICP-MS

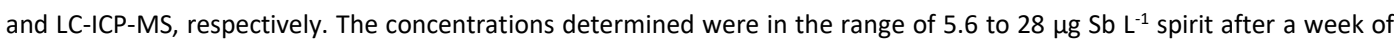
storage at 60 ㅇ. In which case, inorganic $\mathrm{Sb}(\mathrm{V})$ and $\mathrm{Sb}(\mathrm{III})$ became the predominant species in comparison to the "novel" organic Sb complex.

\section{Introduction}

Polyethylene terephthalate (PET) is the fastest growing plastic used for food packaging applications as a result of its popular use for replacing glass containers. Specifically, PET is used in all sizes of soft drinks and mineral water bottles, which are produced by injection stretch blow moulding. ${ }^{1-3}$ PET is also thermoformed to make trays and pots used for cooking and heating foods in both conventional and microwave ovens.

Food packaging has the main function of protecting food from contamination. This necessitates the requirement that the packaging material is inert enough to not cause food contamination during the entirety of its contact period, from the production process until final consumption of the packaged food. For this reason migration mechanisms involving chemicals present in the packaging to the food matrices need to be studied in detail. In the case of PET, significant amounts of antimony ( $\mathrm{Sb}$ ) can be found in the plastic, which come from the catalyst in the form of antimony trioxide or triacetate used during the polymer manufacturing. ${ }^{3,4}$ Therefore, due to the common use of PET as a packaging material by the food industry, Sb frequently comes into contact with food and drink. Consequently, Sb has been observed at slightly elevated concentrations in products for human consumption.

\footnotetext{
a. Section of Analytical Chemistry, University of Barcelona, Martí i Franqués, 1-11, 08028 Barcelona, Spain

b. Department of Chemistry, University of Crete, Voutes, 71003 Heraklion, Greece.

c. Environmental Chemical Processes Laboratory.

+ Dedicated to the memory of Professor Joseph A Caruso.

Electronic Supplementary Information (ESI) available: [details of any supplementary information available should be included here]. See DOI: 10.1039/x0xx00000x
}

The toxicological properties of $\mathrm{Sb}$ depend on its chemical form and oxidation state. The semimetal is found in organic and inorganic compounds in two oxidation states. For the inorganic forms, $\mathrm{Sb}(\mathrm{III})$ is 10 times more toxic than $\mathrm{Sb}(\mathrm{V}) .5,6$ The $\mathrm{Sb}$ complexes with organic ligands are considered to be less toxic than inorganic $\mathrm{Sb}$. In addition, $\mathrm{Sb}$ is considered a priority pollutant by the European Union (EU) ${ }^{7}$ and the United States Environmental Protection Agency (USEPA). ${ }^{8}$

Several studies have reported on the determination of total Sb concentration in PET packaging, most of which are used for mineral water storage. Values between 100 and $400 \mathrm{mg} \mathrm{kg}^{-1}$ have been reported. ${ }^{9-19}$ This is due to significant remains of the semimetal on the plastic polymer chain once the manufacture of PET is finished. $3,11,14$

In addition to the extensive use of PET for water storage, in some countries there is an increasing trend for reuse of PET containers for the storage of various foodstuffs, especially bulk goods. A common practice is the storage of alcoholic beverages in PET bottles. Although alcoholic beverages tend to be stored in glass containers, in some countries, such as Greece, it is typical to store local homemade spirits, such as raki or tsipouro, in PET bottles in order to ease their transport.

Greek raki ( $\rho \alpha \kappa n$ ) or tsikoudia is an alcoholic beverage made on the island of Crete by distilling pomace (pieces of grapes including stems and seeds) pressed during the winemaking process. The resulting spirit is similar to tsipouro made on the mainland of Greece. These spirits do not contain any aniseed as does the Greek drink ouzo or the Turkish raki. ${ }^{20}$ These are similar to other Mediterranean alcoholic beverages, such as Spanish pomace and Italian grappa, in terms of organoleptic properties, chemical composition and manufacturing 
techniques. The final ready-to-consume product of raki or tsipouro contains approximately a $40-65 \%$ of alcohol by volume. ${ }^{21}$

Spirits present a complex matrix due to the presence of different organic acids, among other organic substances. This fact, among others, may promote the migration of Sb from the PET bottle to the beverage, leading to concentrations in the order of $\mu \mathrm{g} \mathrm{L}^{-1}$. In this way, Sb migration studies from PET into food products is a good tool for providing useful information regarding the potential risk associated with the presence of antimony under different storage conditions. It has been reported that several physicochemical factors influence antimony migration, among which storage time and temperature predominate, in addition to factors like the type of PET and matrix characteristics of the beverage. ${ }^{22}$ Following migration, $\mathrm{Sb}$ is found in the beverage or spirit as inorganic $\mathrm{Sb}(\mathrm{V})$ and $\mathrm{Sb}(\mathrm{III})$, as well as in complexed forms, depending on the matrix composition.

Since limited information has been published on the determination of metal species in alcoholic beverages, in particular there is no information about the determination of antimony (total and species) in PET bottled spirits, this paper deals with the study of the presence of antimony in PET bottled Greek raki and tsipouro. As this type of sample has a complex matrix and a significant alcohol content, the analysis of total $\mathrm{Sb}$ and species concentration was assessed, together with the elucidation of the structure of the $\mathrm{Sb}$ species present. In addition, since scarce information regarding the Sb migration processes in PET bottled beverages has been found, the Sb migration behaviour at elevated storage temperature in raki samples has also been investigated in the present paper.

\section{Experimental}

\section{Instrumentation}

Total Sb content was determined using inductively coupled plasma mass spectrometry (ICP-MS) Perkin Elmer NexION 300XX model with $\mathrm{Rh}$ as the internal standard. The ion intensity at $\mathrm{m} / \mathrm{z} 121$ (121Sb) was monitored. A quaternary pump HPLC system (Perkin Elmer Flexar) equipped with an autosampler with an injection volume between 0.01 and $2000 \mu \mathrm{L}$ and an anion exchange column was coupled to the NexION 300X ICP$\mathrm{MS}$ for $\mathrm{Sb}$ speciation. For the instrument control and data acquisition Chromera software was used.

The experimental conditions used with the LC-ICP-MS were the following: PRP-X100 column $(125 \times 4.1 \mathrm{~mm}$ Hamilton, $10 \mu \mathrm{m}$ particle size, USA) operated at room temperature using mobile phases of $10 \mathrm{mM}$ ethylenediaminetetraacetic acid (EDTA) at $\mathrm{pH}$ 4.0 with $0.5 \%$ methanol at a flow rate of $1.5 \mathrm{~mL} \mathrm{~min}^{-1}$ (LC Method A) or $10 \mathrm{mmol} \mathrm{L}^{-1}$ ammonium formate with $2 \%$ of methanol at a flow rate of $1.0 \mathrm{~mL} \mathrm{~min}^{-1}$ (LC Method B).

Molecular mass spectrometry was used for the characterization of the structure of antimony complexes. A Thermo Scientific LCQ Advantage ion trap mass spectrometer with a sonic spray ionisation (SSI) source was used. The SSI source has been reported to be an energetically mild ionization source for metal complexes, suitable for analysing easily oxidized metal species, as well as capable for providing simultaneous negative and positive ion generation. The applied SSI conditions are detailed elsewhere. ${ }^{23}$

For antimony species characterisation, a liquid chromatography system was coupled to the SSI-MS by a PEEK sleeve. A quaternary pump model Shimadzu LC-20AD equipped with a manual stainless steel sampler injector (Rheodyne Model $7125 \mathrm{i}$ ) with a $2 \mu \mathrm{L}$ loop. The separation of antimony species was performed in analytical RP-C18 columns Shim-pack XR-ODS. The mobile phase used was a mixture of methanol and $0.1 \%$ formic acid at flow $0.1 \mathrm{~mL} \mathrm{~min}^{-1}$. For the instrument control and data acquisition Xcalibur software was used. Whereas for structural elucidation using High Resolution Mass Spectrometry (HRMS), a Thermo Fisher Scientific LTQ Orbitrap Velos equipped with a thermally assisted electrospray ionization source was used. The instrument was operated in negative mode, applying the following parameters: ESI voltage was $-2.5 \mathrm{kV}$; capillary and vaporizer temperatures were $320 \circ \mathrm{C}$; sweep gas, auxiliary gas and sheath gas flow rate were 2, 10 and 40 arbitrary units, respectively, and the tube lens was held at $50 \mathrm{~V}$. For tandem MS experiments, the normalised collision energy (NCE) ranged from 20 to $50 \%$, depending on the ion, and nitrogen was used as collision gas (1.5 mTorr).

\section{Reagents and standards}

Ultrapure water with $18 \mathrm{M} \Omega \mathrm{cm}^{-1}$ conductivity (Millipore, Bedford, MA, USA) was used for making up volume standards and reagents. $1000 \mathrm{mg} \mathrm{L}^{-1}$ stock standard solutions of $\mathrm{Sb}$ (III) and $\mathrm{Sb}(\mathrm{V})$ were prepared by dissolving appropriate amounts of potassium antimony (III) oxide tartrate hemihydrate (Fluka, Neu-Ulm, Germany) and potassium hexahydroxoantimonate (Riedel de-Haën, Seelze, Germany) in water, respectively. The stock standard solutions were stored in polyethylene bottles at $4^{\circ} \mathrm{C}$. The working standard solutions were prepared daily by dilution in the mobile phase used for speciation analysis and in acidic medium (nitric acid, Panreac) for total analysis.

The mobile phases were prepared daily by dissolving EDTA, ammonium formate or formic acid (Panreac) in water. In the case of the EDTA mobile phase, the $\mathrm{pH}$ was adjusted with dilute ammonia (Panreac) and then passed through a $0.45 \mu \mathrm{m}$ filter (Millipore type HA).

\section{Selection of samples}

A total of 12 spirit samples from local stores and suppliers were selected for the determination of Sb: 9 samples of Greek raki (tsikoudia) and 3 samples of Greek tsipouro. Among these, 2 samples of both raki and tsipouro were stored in glass bottles for comparison purposes in terms of antimony concentration. Total $\mathrm{Sb}$ and species content were determined by ICP-MS and LC-ICP-MS, respectively. Among these samples, 2 PET bottled raki samples were selected for the determination of $\mathrm{Sb}$ by mass spectrometry and 6 PET bottled raki samples were further selected for the performance of migration studies under controlled temperature conditions. 


\section{Determination of antimony}

\section{Total antimony in raki by ICP-MS}

Samples were pumped into the nebulizer together with the internal standard $\left(2 \% \mathrm{HNO}_{3}\right.$ acid) by means of a T-piece mixer. An additional line was used for waste removal. The samples were quantified by means of an external calibration curve using total $\mathrm{Sb}$ standards from $0.1 \mu \mathrm{g} \mathrm{L}^{-1}$ to $10 \mu \mathrm{g} \mathrm{L}^{-1}$.

\section{Antimony speciation by LC-ICP-MS}

Samples were directly injected to the LC-ICP-MS system under the conditions aforementioned. Antimony species in the extracts were identified by comparison of retention times with those of standards. Antimony in the samples was quantified by means of external calibration curves using $\mathrm{Sb}(\mathrm{III})$ and $\mathrm{Sb}(\mathrm{V})$ standards from $0.1 \mu \mathrm{g} \mathrm{L}^{-1}$ to $10 \mu \mathrm{g} \mathrm{L}-1$.

\section{Mass spectrometric analysis of unknown antimony species}

For the operation of SSI-MS, a $15-20 \mathrm{~cm}$ long polyimide coated fused-silica capillary $(100 \mu \mathrm{m}$ id. $\times 200 \mu \mathrm{m}$ od) was inserted into the pneumatic nebulizer's sample uptake channel till it is aligned with the glass nebulizer spray tip. The fused silica capillary is secured in place by tightening a PEEK sleeve around it in the back of the nebulizer. The tip of nebuliser was placed approximately $1-3 \mathrm{~mm}$ from the mass spectrometer orifice. The temperature of the heated ion transfer capillary was set to $300 \circ \mathrm{C}$, the source induced dissociation (SID) voltage applied was $5 \mathrm{~V}$, the collision energy was $20 \%$ and the nitrogen gas pressure used for nebulization was between 40-60 psi. ${ }^{23}$ For HRMS analysis, samples were analysed by direct infusion using a syringe and a syringe pump at a flow rate of $10 \mu \mathrm{L} \mathrm{min}{ }^{-1}$.

\section{Computational Details of unknown antimony species}

Several molecular models of the Sb complexes were created in order to explore the variety of the possible structures of the same molecular mass but with different connectivity of the atoms by conducting quantum chemistry calculations. Sets of possible ligands obeying the corresponding chemical composition $\mathrm{C}_{7} \mathrm{H}_{14} \mathrm{O}_{12} \mathrm{~S}_{2} \mathrm{Sb}$ (as determined using high resolution mass spectrometry) were created based on chemical intuition

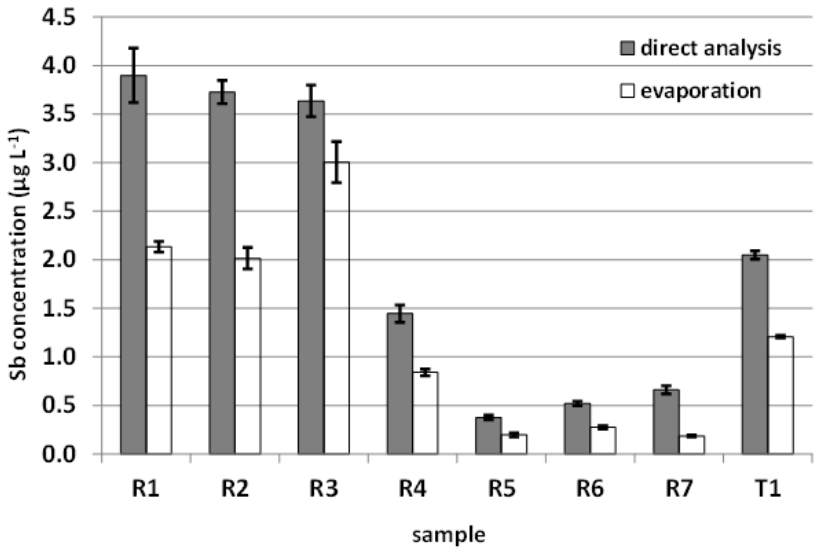

Figure 1 Total Sb concentration in PET bottled raki and tsipouro samples. R1 - R7: PET bottled raki; T1: PET bottled tsipouro $(n=3)$ in order to build these models. Moreover, both the Sb oxidation states III and V were taken into account during calculations. The prediction of the geometries of the $\mathrm{Sb}$ complexes was based on the Density Functional Theory (DFT) method and the RI-B$\mathrm{P} /$ def2-SVP computational model was used during calculations. ${ }^{24}$ Tight convergence criteria were used for both the self-consistent field procedure $\left(10^{-7} \mathrm{au}\right)$ and the gradient $\left(10^{-4}\right.$ $\mathrm{au})$. The corresponding auxiliary basis sets were used for the Resolution of Identity (RI) approximation. ${ }^{25}$ During the optimization of the geometry, no symmetry restrictions were applied. The calculations were performed with the Turbomole quantum chemistry package. ${ }^{26}$

\section{Results and Discussion}

\section{Analysis of total Sb by ICP-MS}

Total Sb content was determined in all samples using 2 different sample preparation approaches: direct analysis following sample dilution and analysis after sample evaporation and appropriate dilution. Both approaches we performed in order to reduce the ethanol content in the samples and thus prevent plasma instability. The evaporation process was performed in a water bath at 50 ㅇ for 1 hour. Prior to analysis, samples and evaporated samples were diluted four and two times, respectively, in acidic media.

The Sb content in glass bottled samples was found to be lower than the limit of detection (LOD was in the low ng Sb per $L$ range), whereas PET bottled samples showed significantly higher concentrations. The Sb concentrations determined in the PET bottled samples are plotted in Figure 1. Antimony concentration differences were observed for the same samples that had been prepared using the two different approaches: the concentrations obtained with the direct analysis approach were between $0.4-4 \mu \mathrm{g} \mathrm{L}^{-1}$, whereas the values obtained using the evaporation process were systematically lower for all samples: $0.2-3 \mu \mathrm{g} \mathrm{L}^{-1}$. RSD values were $\leq 10$ in all cases. The direct analysis of samples following dilution gave slightly higher $\mathrm{Sb}$ concentrations, which could be due to a matrix enhancement effect caused by the ethanol or the possible loss of the Sb content during the alcohol evaporation process for the evaporated samples. It was observed that more than half of the PET samples showed concentrations higher than $1 \mu \mathrm{L} \mathrm{L}^{-1}$. These values are higher than those typically obtained for water samples stored in PET containers, which have been reported in previous work. ${ }^{19}$ This difference could be partially related to the samples' high ethanol content as well as the presence of potential organic ligands that may be promoting Sb extraction. Ethanol is used as a food simulant for alcoholic foodstuffs to perform the migration test stipulated in the EU Directive 97/48/CE. ${ }^{27}$ Spirits typically have a high content of fusel alcohols, organic volatile molecules and sugar, which could ease or promote the migration of Sb from the PET matrix. Moreover, 3 PET bottled raki (tsikoudia) samples had Sb concentrations close to $4 \mu \mathrm{g} \mathrm{L}^{-1}$, which is quite close to the limit established by the EU for drinking waters $\left(5 \mu \mathrm{g} \mathrm{L}^{-1}\right)$. However, as consumption of such spirits is relatively low for the general public their $\mathrm{Sb}$ 

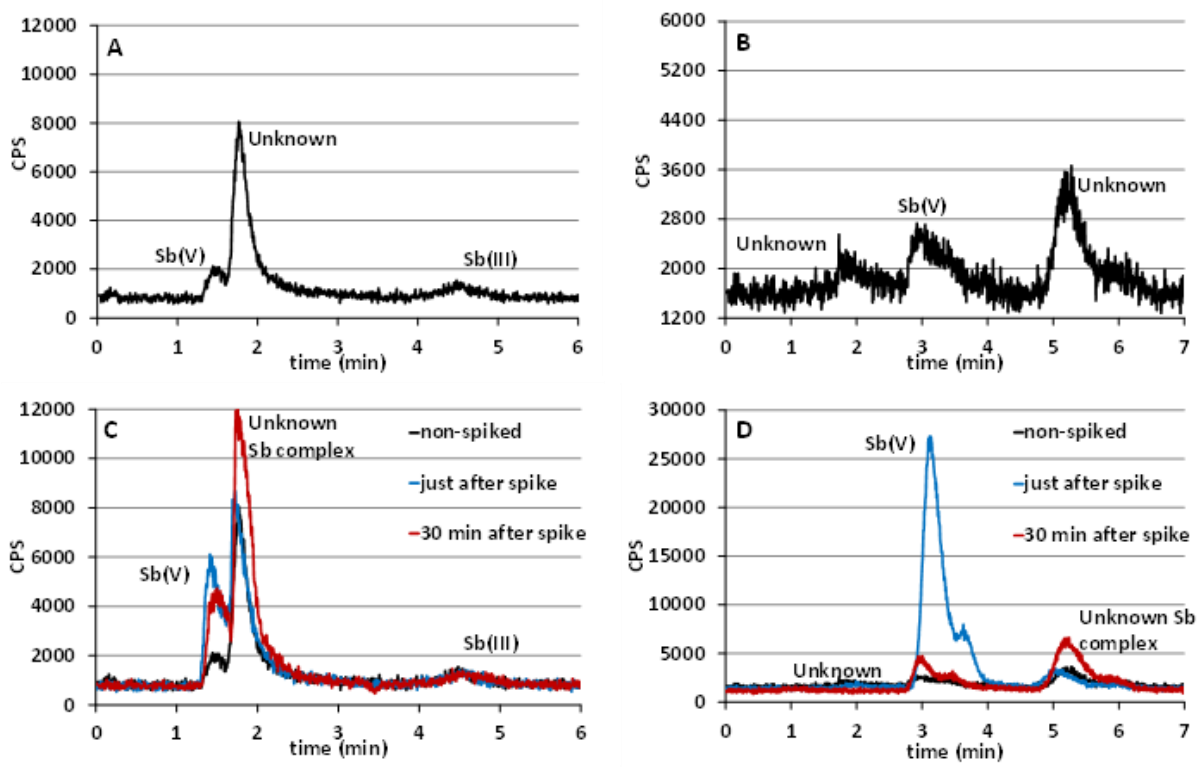

Figure 2 Chromatograms obtained from raki R2 by LC-ICP-MS using EDTA $10 \mathrm{mmol} \mathrm{L}-10 \mathrm{pH} 4$ with $0.5 \%$ of methanol and ammonium formate $8 \mathrm{mmol} \mathrm{L}^{-1}$ with $2 \%$ of methanol as mobile phase $(\mathrm{A}, \mathrm{B})$ and spike tests with $2 \mu \mathrm{g} \mathrm{L} \mathrm{L}^{-1}$ of $\mathrm{Sb}(\mathrm{V})(\mathrm{C}, \mathrm{D})$.

content does not seem to be of significant concern for public health. In addition, in the present study these spirits have been stored in the PET bottles for over 12 months prior to analysis. It is our ambition, however, to try and further understand the physicochemical processes responsible for Sb migration from the PET material to the spirit.

\section{Antimony speciation by using LC-ICP-MS}

After the determination of total $\mathrm{Sb}$ in raki and tsipouro, $\mathrm{Sb}$ speciation in the PET bottled samples was carried out by using LC-ICP-MS. Two different separation conditions both based on anion exchange chromatography were assessed for the separation of Sb species. The first method used a mobile phase containing EDTA $10 \mathrm{mmol} \mathrm{L}^{-1}$ at $\mathrm{pH} 4.0$ with $0.5 \%$ of methanol run at a flow of $1.5 \mathrm{~mL} \mathrm{~min}^{-1}$ (LC Method $A$ ). This approach has already been described elsewhere. ${ }^{19}$ The second separation method used a mobile phase containing ammonium formate 10

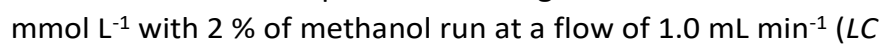
Method $B$ ). This mobile phase has previously been used for the separation of several $\mathrm{Sb}(\mathrm{V})$ complexes in $\mathrm{Sb}$ spiked yogurt samples. ${ }^{28}$ Inorganic $\mathrm{Sb}(\mathrm{V})$ and $\mathrm{Sb}(\mathrm{III})$ standards were also analysed using both separation methods in order to help identify the Sb species detected in the raki samples.

The chromatograms resulting from monitoring $\mathrm{Sb}$ in the raki samples contained a maximum of $3 \mathrm{Sb}$ peaks for each of the chromatographic methods. As an example, Figure $2 \mathrm{~A}$ and $\mathrm{B}$ depicts the chromatograms obtained from the analysis of sample R2 using LC Methods A and B, respectively. When using EDTA as the mobile phase (LC Method A), the first and the third peak have the same retention times as does inorganic $\mathrm{Sb}(\mathrm{V})$ and $\mathrm{Sb}$ (III) standards, respectively. Thus, raki peaks 1st and 3rd correspond to non-complexed $\mathrm{Sb}(\mathrm{V})$ and $\mathrm{Sb}(\mathrm{III})$ species, respectively. The inorganic $\mathrm{Sb}$ (III) species is only present in raki samples R1 - R3. The second peak, which is the main Sb species in all the analysed raki samples, has a retention time slightly longer than inorganic $\mathrm{Sb}(\mathrm{V})$, corresponding to an unknown $\mathrm{Sb}$ species. The Sb peaks obtained using LC Method B correspond to $\mathrm{Sb}(\mathrm{V})$ species, as inorganic $\mathrm{Sb}(\mathrm{III})$ does not elute using these separation conditions. ${ }^{28}$ The second peak, observed using LC Method $\mathrm{B}$, has the same retention time as the $\mathrm{Sb}(\mathrm{V})$ standard, therefore, it corresponds to non-complexed $\mathrm{Sb}(\mathrm{V})$ species (Fig. 2 B). The other two peaks may correspond to unknown complexes of $\mathrm{Sb}$.

To further identity of the $\mathrm{Sb}$ species present in the raki samples, tests were performed by spiking with $\mathrm{Sb}(\mathrm{V})$ and $\mathrm{Sb}(\mathrm{III})$ standards. Samples were spiked with a concentration of $2 \mu \mathrm{g} \mathrm{Sb}$ $\mathrm{L}^{-1}$ using each $\mathrm{Sb}$ species. On the one hand, it was verified that the third peak observed when using LC Method A corresponds to $\mathrm{Sb}(\mathrm{III})$ species, as the intensity increased when spiking with inorganic $\mathrm{Sb}(\mathrm{III})$. On the other hand, samples spiked with $\mathrm{Sb}(\mathrm{V})$ were analysed using each of the two LC methods $A$ and $B$. The results obtained are depicted in Figure $2 C$ and $D$, respectively. When samples were analysed using LC Method A just after spiking with $\mathrm{Sb}(\mathrm{V})$, only the intensity of the non-complexed $\mathrm{Sb}(\mathrm{V})$ increased, as can be seen with respect to the non-spiked sample (Fig. 2C). However, when repeating the analysis 30 minutes later, the signal of $\mathrm{Sb}(\mathrm{V})$ decreased whereas the intensity of the second peak (unknown Sb species) increased. When using LC Method B the third peak was observed to increase slightly.

Moreover, it should be taken into account that the loss and gain of the area of $\mathrm{Sb}(\mathrm{V})$ and the unknown $\mathrm{Sb}$ species, respectively, $30 \mathrm{~min}$ after spiking, is different for each of the two separation methods. When using the EDTA mobile phase (LC Method A), although the signal gain for the unknown species is slightly higher than the signal loss for $\mathrm{Sb}(\mathrm{V})$ species, the \% gain and loss, respectively, in terms of area and concentration are similar. However, with the ammonium formate method (LC Method $\mathrm{B}$ ), the signal loss for non-complexed $\mathrm{Sb}(\mathrm{V})$ is much more significant than the signal gain for the unknown species, 
which demonstrates that there is a loss of the unknown $\mathrm{Sb}$ species when using LC Method B. Thus suggesting that a significant portion of the unknown Sb species may be noneluting $\mathrm{Sb}(\mathrm{III})$ species.

From the results obtained, the use of the EDTA mobile phase gave better elution performance. However, when using other detection systems such as electrospray ionization (ESI) -MS, the use of ammonium formate (LC Method B) is to be preferred in order to avoid problems related to the use of non-volatile salts or buffers.

Once the most suitable separation method was selected (LC method A), i.e. giving the highest recovery, Sb species in the raki samples were quantified by means of external calibration curves of $\mathrm{Sb}(\mathrm{V})$ and $\mathrm{Sb}(\mathrm{III})$, which were prepared in $40 \%$ of ethanol to simulate the sample matrix. As the unknown species has a retention time very similar to the $\mathrm{Sb}(\mathrm{V})$, it was quantified using the $\mathrm{Sb}(\mathrm{V})$ calibration curve. Column recoveries calculated with respect to total $\mathrm{Sb}$ contents ranged from $70-110 \%$ except for sample R1, which gave a slightly lower value (62\%). This fact could be due to the presence of other minor Sb species that did not elute from the column. RSD values obtained were $\leq 10 \%$ in all cases. However, for three samples (R5 - R7) with total Sb content around $0.5 \mu \mathrm{g} \mathrm{L}^{-1}$ or even lower, high recovery values were obtained, which demonstrates the analytical challenge resulting from the extended sample dilution needed for the analysis. Even though the unknown species, which is the predominant $\mathrm{Sb}$ species in all samples, was quantified using a different standard, the Sb species recoveries obtained for five of the samples analysed were acceptable.

\section{Analysis of unknown Sb complex by using LC-SSI- ion trap low resolution MS and direct infusion ESI- orbitrap high resolution MS}

Optimization of the separation process

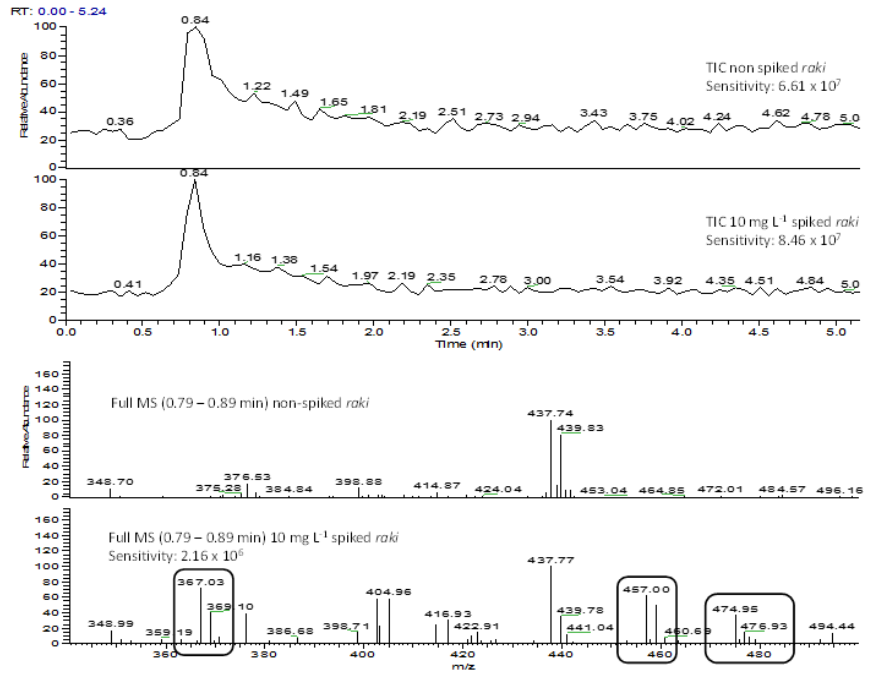

Figure 3 TIC of non-spiked and $10 \mathrm{mg} \mathrm{Sb}(\mathrm{V}) \mathrm{L}^{-1}$ spiked raki $\mathrm{R} 1$ together with the average spectra of the 0.84 -minute peak signal.

The analysis of Sb species by LC-ICP-MS showed that raki samples had an unknown Sb complex as their major Sb species. In order to determine the structure of this complex, several studies by SSI-MS were performed by using ammonium formate as mobile phase.

First of all, the two raki samples with the highest concentration of $\mathrm{Sb}, \mathrm{R} 1$ and $\mathrm{R} 2$, were selected and analysed by ESI-MS with direct infusion at the conditions described in section 2.4. The samples were analysed both directly and spiked at different concentration levels of $\mathrm{Sb}(\mathrm{V}): 10 \mu \mathrm{g} \mathrm{L}^{-1}, 100 \mu \mathrm{g} \mathrm{L}^{-1}, 1$ $\mathrm{mg} \mathrm{L}^{-1}$ and $10 \mathrm{mg} \mathrm{L}^{-1}$. The spectra showed plenty of ion signals and a high level background in all cases from which it was not possible to identify any Sb-containing ions. Therefore, it was decided to analyse the samples by LC-SSI-MS with the

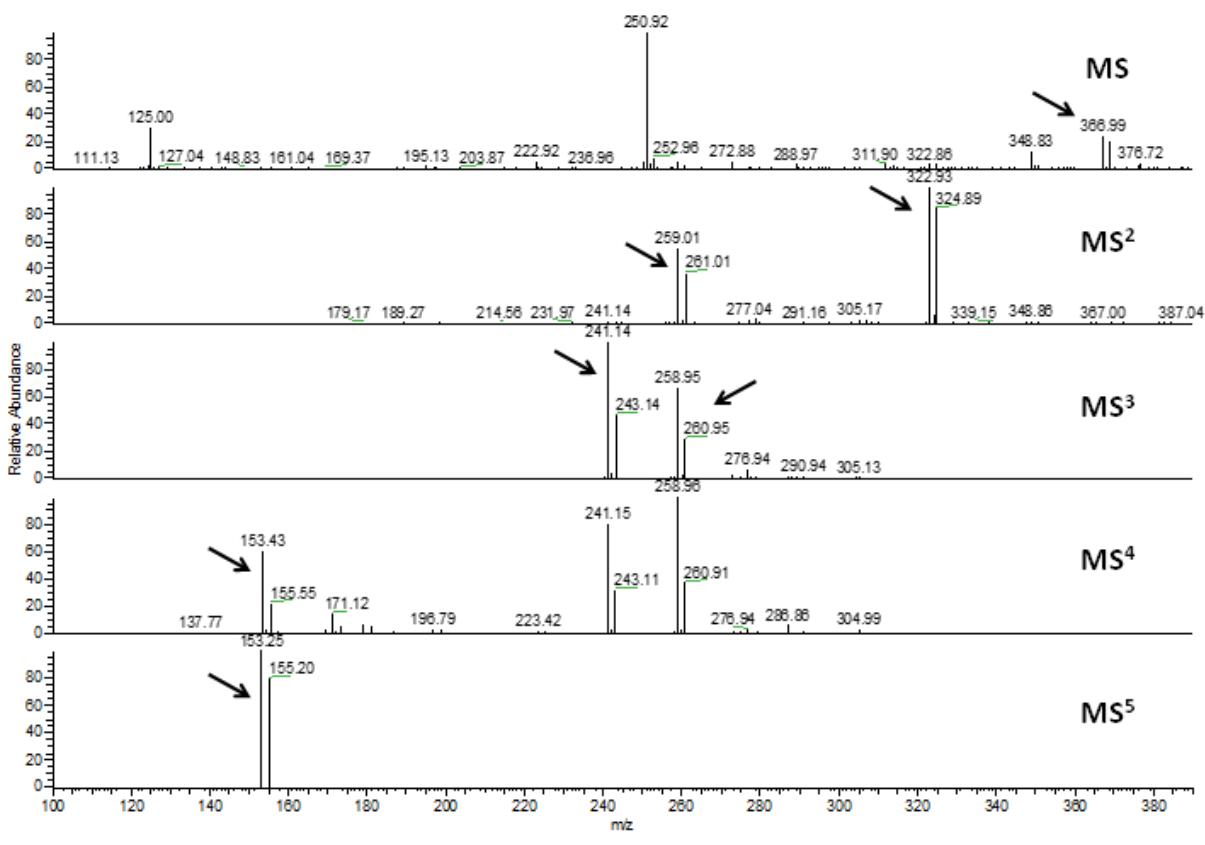

Figure 4. MS, $\mathrm{MS}^{2}$ on $\mathrm{m} / \mathrm{z} 367, \mathrm{MS}^{3}$ on $\mathrm{m} / \mathrm{z} 259, \mathrm{MS}^{4}$ on $\mathrm{m} / \mathrm{z} 241$ and $\mathrm{MS}^{5}$ on $\mathrm{m} / \mathrm{z} 153$ spectra of the organic Sb complex in raki $\mathrm{R} 1$ spiked sample with $10 \mathrm{mg} \mathrm{L}^{-1}$ of $\mathrm{Sb}(\mathrm{V})$. Collision energy for $\mathrm{MS}$ and $\mathrm{MS}^{2}: 20 \%$. Collision energy for $\mathrm{MS}^{3}$ and $\mathrm{MS}^{4}: 25 \%$. 
Table 1. Assignment of prominent ions observed for the unknown Sb complex in raki spiked to contain $10 \mathrm{mg}$ Sb L-1.

\begin{tabular}{|c|c|c|c|c|}
\hline $\begin{array}{c}\mathrm{MS}^{\mathrm{n}} \\
\mathrm{n}\end{array}$ & Molecular ion $(\mathrm{m} / \mathrm{z})$ & $\begin{array}{c}\text { Elemental Composition / } \\
\text { Proposed Formula }\end{array}$ & Product ion $(\mathrm{m} / \mathrm{z})$ & Product ion Assignment \\
\hline 2 & $474.89456-476.89502$ & $\begin{array}{c}\mathrm{C}_{7} \mathrm{H}_{14} \mathrm{O}_{12} \mathrm{~S}_{2} \mathrm{Sb} \\
{\left[\mathrm{Sb}\left(\mathrm{C}_{2} \mathrm{H}_{5} \mathrm{O}_{4} \mathrm{~S}\right)_{2}\left(\mathrm{C}_{3} \mathrm{H}_{3} \mathrm{O}_{3}\right)(\mathrm{OH})\right]^{-}}\end{array}$ & $456.88419-458.88443$ & $\begin{array}{l}{[\mathrm{M}-18]^{-}} \\
{\left[\mathrm{M}-\mathrm{H}_{2} \mathrm{O}\right]^{-}}\end{array}$ \\
\hline \multirow[t]{2}{*}{3} & \multirow[t]{2}{*}{$456.88419-458.88443$} & $\begin{array}{c}\mathrm{C}_{7} \mathrm{H}_{12} \mathrm{O}_{11} \mathrm{~S}_{2} \mathrm{Sb} \\
{\left[\mathrm{Sb}\left(\mathrm{C}_{2} \mathrm{H}_{5} \mathrm{O}_{4} \mathrm{~S}\right)\left(\mathrm{C}_{2} \mathrm{H}_{3} \mathrm{O}_{3} \mathrm{~S}\right)\right.} \\
\left.\left(\mathrm{C}_{3} \mathrm{H}_{3} \mathrm{O}_{3}\right)(\mathrm{OH})\right]^{-}\end{array}$ & $366.90710-368.90755$ & $\begin{array}{c}{[\mathrm{M}-90]^{-}} \\
{\left[\mathrm{M}-\left(\mathrm{C}_{2} \mathrm{H}_{2} \mathrm{O}_{2} \mathrm{~S}\right)\right]^{-}}\end{array}$ \\
\hline & & & $348.89706-350.89719$ & $\begin{array}{c}{[\mathrm{M}-108]^{-}} \\
{\left[\mathrm{M}-\left(\mathrm{C}_{2} \mathrm{H}_{4} \mathrm{O}_{3} \mathrm{~S}\right)\right]^{-}}\end{array}$ \\
\hline \multirow[t]{2}{*}{4} & \multirow[t]{2}{*}{$366.90710-368.90755$} & $\begin{array}{c}\mathrm{C}_{5} \mathrm{H}_{10} \mathrm{O}_{9} \mathrm{SSb} \\
{\left[\mathrm{Sb}\left(\mathrm{C}_{2} \mathrm{H}_{5} \mathrm{O}_{4} \mathrm{~S}\right)\left(\mathrm{C}_{3} \mathrm{H}_{3} \mathrm{O}_{3}\right)(\mathrm{OH})_{2}\right]^{-}}\end{array}$ & $322.88165-324.88183$ & $\begin{array}{c}{[\mathrm{M}-44]^{-}} \\
{\left[\mathrm{M}-\left(\mathrm{C}_{2} \mathrm{H}_{4} \mathrm{O}\right)\right]^{-}}\end{array}$ \\
\hline & & & 258.91977-260.92005 & $\begin{array}{c}{[\mathrm{M}-108]^{-}} \\
{\left[\mathrm{M}-\left(\mathrm{C}_{2} \mathrm{H}_{4} \mathrm{O}_{3} \mathrm{~S}\right)\right]^{-}}\end{array}$ \\
\hline 4 & 348.89706-350.89719 & $\begin{array}{c}\mathrm{C}_{5} \mathrm{H}_{8} \mathrm{O}_{8} \mathrm{SSb} \\
{\left[\mathrm{Sb}\left(\mathrm{C}_{2} \mathrm{H}_{3} \mathrm{O}_{3} \mathrm{~S}\right)\left(\mathrm{C}_{3} \mathrm{H}_{3} \mathrm{O}_{3}\right)(\mathrm{OH})_{2}\right]^{-}}\end{array}$ & $322.88165-324.88183$ & $\begin{array}{c}{[\mathrm{M}-26]^{-}} \\
{\left[\mathrm{M}-\left(\mathrm{C}_{2} \mathrm{H}_{2}\right)\right]^{-}}\end{array}$ \\
\hline \multirow[t]{5}{*}{5} & \multirow[t]{2}{*}{$322.88165-324.88183$} & $\begin{array}{c}\mathrm{C}_{3} \mathrm{H}_{6} \mathrm{O}_{8} \mathrm{SSb} \\
{\left[\mathrm{Sb}\left(\mathrm{HO}_{3} \mathrm{~S}\right)\left(\mathrm{C}_{3} \mathrm{H}_{3} \mathrm{O}_{3}\right)(\mathrm{OH})_{2}\right]^{-}}\end{array}$ & 304.87091-306.87125 & $\begin{array}{l}{[\mathrm{M}-18]^{-}} \\
{\left[\mathrm{M}-\mathrm{H}_{2} \mathrm{O}\right]^{-}}\end{array}$ \\
\hline & & & 258.91977-260.92005 & $\begin{array}{c}{[\mathrm{M}-64]^{-}} \\
{\left[\mathrm{M}-\left(\mathrm{O}_{2} \mathrm{~S}\right)\right]^{-}}\end{array}$ \\
\hline & 304.87091-306.87125 & $\begin{array}{c}\mathrm{C}_{3} \mathrm{H}_{4} \mathrm{O}_{7} \mathrm{SSb} \\
{\left[\mathrm{Sb}\left(\mathrm{HO}_{3} \mathrm{~S}\right)\left(\mathrm{C}_{3} \mathrm{H}_{3} \mathrm{O}_{3}\right)(\mathrm{O})\right]^{-}}\end{array}$ & $240.90912-242.90948$ & $\begin{array}{c}{[\mathrm{M}-64]^{-}} \\
{\left[\mathrm{M}-\left(\mathrm{O}_{2} \mathrm{~S}\right)\right]^{-}}\end{array}$ \\
\hline & 258.91977-260.92005 & $\begin{array}{c}\mathrm{C}_{3} \mathrm{H}_{6} \mathrm{O}_{6} \mathrm{Sb} \\
{\left[\mathrm{Sb}\left(\mathrm{C}_{3} \mathrm{H}_{3} \mathrm{O}_{3}\right)(\mathrm{OH})_{3}\right]^{-}}\end{array}$ & $240.90912-242.90948$ & $\begin{array}{c}{[\mathrm{M}-18]^{-}} \\
{\left[\mathrm{M}-\mathrm{H}_{2} \mathrm{O}\right]^{-}}\end{array}$ \\
\hline & $240.90912-242.90948$ & $\begin{array}{c}\mathrm{C}_{3} \mathrm{H}_{4} \mathrm{O}_{5} \mathrm{Sb} \\
{\left[\mathrm{Sb}\left(\mathrm{C}_{3} \mathrm{H}_{3} \mathrm{O}_{3}\right)(\mathrm{OH})(\mathrm{O})\right]^{-}}\end{array}$ & $152.89354-154.89395$ & $\begin{array}{c}{[\mathrm{M}-88]^{-}} \\
{\left[\mathrm{M}-\left(\mathrm{C}_{3} \mathrm{H}_{4} \mathrm{O}_{3}\right)\right]^{-}}\end{array}$ \\
\hline 6 & $152.89354-154.89395$ & $\begin{array}{c}\mathrm{O}_{2} \mathrm{Sb} \\
{\left[\mathrm{Sb}(\mathrm{O})_{2}\right]^{-}}\end{array}$ & - & - \\
\hline
\end{tabular}

conditions described in sections 2.1 and 2.4. The mobile phase selected was a mixture of $0.1 \%$ formic acid and methanol $80: 20$ and the column length was $3 \mathrm{~cm}$ (reversed phase HPLC). The results showed a peak signal with the same retention time as the dead volume $(0.8 \mathrm{~min})$. Figure 3 shows the Total Ion Chromatogram (TIC) of the non-spiked raki R1 and the spiked one at $10 \mathrm{mg} \mathrm{L}^{-1}$ level together with the corresponding spectra average of the peak signal. For samples spiked with $1 \mathrm{mg} \mathrm{Sb} \mathrm{L}^{-1}$, this signal corresponded to antimony complexes with mass-tocharge ratio $(\mathrm{m} / \mathrm{z})$ of $367-369,457-459,475-477$. In the nonspiked sample and the spiked ones at a concentration level lower than $1 \mathrm{mg} \mathrm{L}^{-1}$, no ion signals matching the isotopic distribution of $\mathrm{Sb}$ were observed.

In order to improve the retention of the Sb complex on reversed phase chromatography two chromatographic parameters were assessed and modified: the composition of the mobile phase and the column length. First of all, raki sample $\mathrm{R} 1$ spiked with $10 \mathrm{mg} \mathrm{L}^{-1}$ of $\mathrm{Sb}(\mathrm{V})$ was analysed using different ratios of formic acid - methanol. The ratio of formic acid $0.1 \%$ solution was increased from the fixed value used in the previous test $(80 \%)$ to $100 \%$. As the percentage of methanol decreases, the retention of the $\mathrm{Sb}$ peak increases slightly, indicating some hydrophobic interaction with the reversed phase stationary phase. However, for organic solvent content lower than $10 \%$, the $\mathrm{Sb}$ peak shows deformation. Thus, the optimum mobile phase ratio arrived at was $90 \%$ of $0.1 \%$ formic acid and $10 \%$ of methanol.

To further increase retention and mass spectrometric sensitivity a $10-\mathrm{cm}$ length column was assessed and the results obtained were compared to those obtained using the $3-\mathrm{cm}$ length column. The spiked R1 sample was analysed and the mobile phase with the optimum ratio ( $90 \%$ of formic acid and $10 \%$ of methanol) was used. As expected, retention time for the unknown $\mathrm{Sb}$ peak increased significantly. These were the optimum conditions used for the analysis of the unknown $\mathrm{Sb}$ species by LC-SSI-MS.

\section{Characterisation of unknown Sb complex}

After the assessment of the optimum conditions for the determination of the unknown Sb complex in raki spiked with $\mathrm{Sb}(\mathrm{V})$, the confirmation and identification of the corresponding Sb species was carried out by studying the fragmentation of the complex by using the tandem mass spectrometry. First of all, the ion with $\mathrm{m} / \mathrm{z} 367$ was selectively monitored and its product ion mass spectra recorded. The obtained fragments containing ions with the $\mathrm{Sb}$ isotopic distribution were further selected and fragmented in subsequent tandem mass spectrometric experiments. Tandem mass spectrometric experiment $\mathrm{MS}^{n}$ $(n=2-5)$ were therefore performed. Figure 4 summarises the mass spectra obtained by tandem mass spectrometry.

During $\mathrm{MS}^{2}$, it can be observed that the complex with $\mathrm{m} / \mathrm{z}$ 367-369 yielded the ions at $\mathrm{m} / \mathrm{z} 323-325$ and $259-261$ with the isotopic distribution typical of the $\mathrm{Sb}$ (even though some mass bias in the ion trap did not give the exact isotope abundances). In $\mathrm{MS}^{3}$, the product ion with $\mathrm{m} / \mathrm{z}$ 323-325 yielded the ion at $\mathrm{m} / \mathrm{z}$ 259-261 and the product ion with $\mathrm{m} / \mathrm{z} 259-261$ yielded the ion at $\mathrm{m} / \mathrm{z}$ 241-243. In $\mathrm{MS}^{4}$, the product ion with $\mathrm{m} / \mathrm{z} 241-243$ yielded the ion at $\mathrm{m} / \mathrm{z} 153-155$. Sb atomic ions were not 
A.<smiles>CC(O)S(=O)(=O)O</smiles>

B<smiles>CC(=O)C(=O)O[Sn](O)(OS(=O)(=O)C(C)O)OS(=O)(=O)C(C)O</smiles>

C.

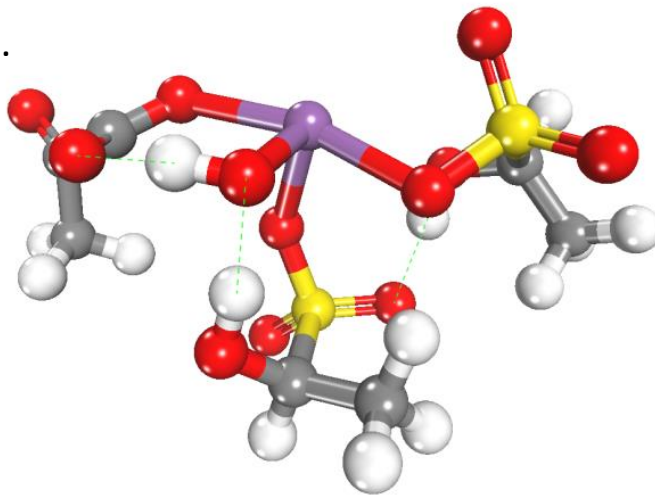

Figure 5. A: Possible reaction product formed from sulphites and ethanol. B: Proposed unknown $\mathrm{Sb}$ complex present in raki derived from high resolution and tandem mass spectrometry data. C: Ball and Stick representation of the geometry of the Sb complex as calculated by DFT. Sb, S, O, C and $\mathrm{H}$ atoms are represented as purple, yellow, red, grey and white spheres, respectively.

detected during $\mathrm{MS}^{5}$ under any of the tested collision energies. During the tandem mass spectrometric analysis a mass loss of 108 was observed during MS² $^{2}$ from ion 367-369 to ion 259-261; and a mass loss of 88 in MS 4 from ion 241-243 to ion 153-155.

After the CID fragmentation of the unknown Sb complex, the mass losses were studied and compared to the possible compounds present in the raki matrix. Tandem mass spectrometry by high resolution MS using a LTQ-ESI-Orbitrap was used to determine the exact mass of the compound and the product ions obtained. This allowed for determination of the elemental composition of the obtained ions and the composition of the mass losses.

In high resolution MS the R1 sample was analysed by direct infusion. As this operation mode provides less sensitivity than the LC-SSI-MS, used in the previous section, it was decided to spike the sample $\mathrm{R} 1$ at a concentration of $100 \mu \mathrm{g} \mathrm{\textrm {L } ^ { - 1 }}$. Full mass spectra showed the same masses as previously described for low resolution ion trap mass spectrometry, i.e. 366.90710; 456.88419; and 474.89456.

After this, tandem mass spectrometry was carried out on these $\mathrm{Sb}$-containing ions in order to obtain the exact mass of all the resulting product ions. For the $\mathrm{m} / \mathrm{z}$ 366.90710, the same product ion formation route, as observed using the low resolution ion trap technique, was obtained. The $\mathrm{m} / \mathrm{z}$ 456.88419 fragmented to the 366.90710 and to another one with the $\mathrm{Sb}$ isotopic distribution profile: 348.89706 . The $\mathrm{m} / \mathrm{z}$ 474.89456 fragmented to the 456.88419 . Figure S1 (Supplementary material) depicts the most relevant tandem mass spectra obtained in this experiment.

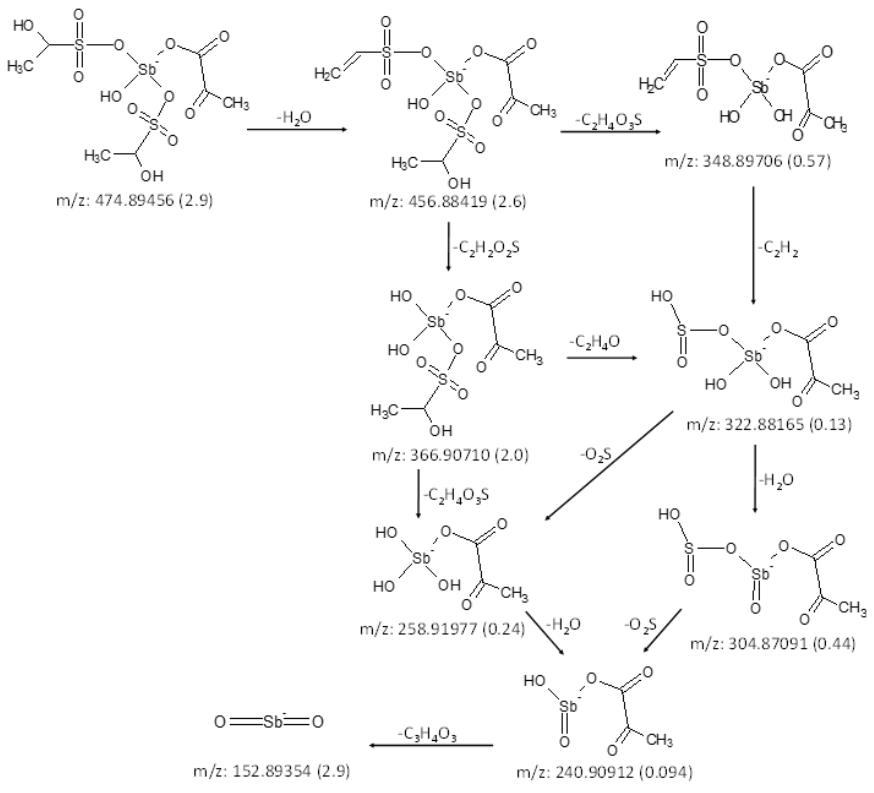

Figure 6. Proposed fragmentation route observed for the novel $\mathrm{Sb}$ complex present in raki. Accurate masses are given below each suggested structure along with mass accuracy in ppm in parentheses.

These results demonstrate that ions with $\mathrm{m} / \mathrm{z} 366.90710$ and 456.88419 resulted from the precursor ion at $\mathrm{m} / \mathrm{z}$ 474.89456 in addition to appearing in the full MS spectrum as well. According to this, the elemental composition of the ion 474.89456 and the fragments obtained was determined using appropriate software (Thermo Xcalibur Qual Browser). First, the program provided more than 10 possible molecular formulas for the target masses, with an error lower than $5 \mathrm{ppm}$. However, after analysing the obtained fragments in the different spectra, only two of the proposals were feasible: $\mathrm{C}_{7} \mathrm{H}_{14} \mathrm{O}_{12} \mathrm{~S}_{2} \mathrm{Sb}$ and $\mathrm{C}_{8} \mathrm{H}_{18} \mathrm{O}_{7} \mathrm{~S}_{4} \mathrm{Sb}$, with an error of 2.9 and $4.7 \mathrm{ppm}$, respectively. It is thought that the antimony complex present in raki corresponds to the first formula, as it presents a lower error and contains fewer sulphur atoms. The isotopic distribution was simulated so as to verify the proposed formulas by the software, obtaining good agreement.

After obtaining the elemental composition, the assignment of the ions obtained in the full MS and the tandem MS was performed. Table 1 summarises the $\mathrm{m} / \mathrm{z}$ obtained with the typical isotopic distribution of the antimony and the molecular formulas obtained, together with the corresponding product ions and losses.

It was observed that the most significant mass losses were 108 and 88. Checking the results obtained, these losses correspond to the following formulas: $\mathrm{C}_{2} \mathrm{H}_{4} \mathrm{O}_{3} \mathrm{~S}$ and $\mathrm{C}_{3} \mathrm{H}_{4} \mathrm{O}_{3}$. As described in the literature, sulphites are commonly used as an additive for several foodstuffs and beverages, such as grapes, wines or beer. ${ }^{29,30}$ Thus, sulphites may be added during the production of the raki and may have reacted with acetaldehyde (resulting from ethanol oxidation), forming the corresponding acetaldehyde bisulphite adduct (Figure 5A). ${ }^{31,32}$ The second molecular formula may correspond to pyruvic acid, a product of alcoholic fermentation. ${ }^{33}$ According to these results, the unknown Sb compound present in raki with a mass of 475 may 


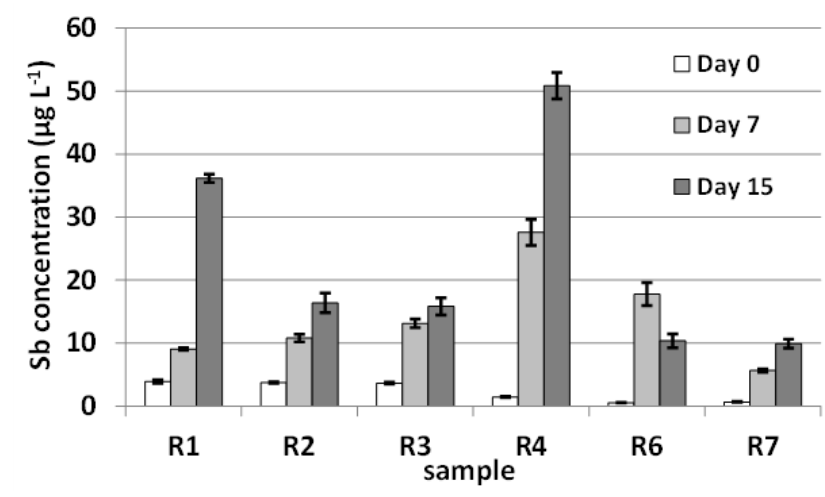

Figure 5. Evolution of total $\mathrm{Sb}$ concentration in PET bottled raki stored at $60 \circ \mathrm{C}$ for 15 days.

be the complex depicted in Figure 5B. According to this structure and the mass losses observed, a proposed fragmentation route, from the precursor ion $(\mathrm{m} / \mathrm{z} 474.89456)$ to the last product $(\mathrm{m} / \mathrm{z} 152.89632)$ is proposed in Figure 6 . The agreement of the measured product ion mass with the proposed structures are given in brackets as ppm values.

\section{Theoretical calculations for proposed unknown Sb complex}

Theoretical optimizations of the geometries of proposed molecular models showed that most of complexes had a tendency to dissociate with respect to their initial geometry and their initial chemical composition of the ligands that were used for each of the models. We were able to identify the most stable $\mathrm{Sb}$ complex with molecular formula $\left[\mathrm{Sb}\left(\mathrm{C}_{2} \mathrm{H}_{5} \mathrm{O}_{4} \mathrm{~S}\right)_{2}\left(\mathrm{C}_{3} \mathrm{O}_{3} \mathrm{H}_{3}\right)(\mathrm{OH})\right]^{-}$(Figure 5C) which is in agreement with the structure derived from the high resolution tandem mass spectrometric analysis. The geometry that can be seen in Fig. 5C corresponds also to the lower in energy conformer that was tested with the same molecular formula mentioned above. The geometry of the complex resembles a distorted pyramidal geometry which is further stabilized by the formation of three hydrogen bonds (ranging from $1.66 \AA$ to $1.69 \AA$, shown in Fig. $5 \mathrm{C}$ with green dashed lines) between hydroxyl anion and the closest oxygen atom of the pyruvic anion, the hydroxyl group of hydroxyethanesulfonic anion with the hydroxyl anion, and the hydroxyl group of one hydroxyethanesulfonic anion with an oxygen atom of the other hydroxyethanesulfonic anion.

\section{Antimony migration into raki}

In this part of the study, the influence of storage time and temperature on Sb migration in raki, was investigated for the six PET bottled raki samples mentioned in section 2.3 (R1 - R4, R6 - R7). The effect of storage time up to 2 weeks at a storage temperature of 60 ㅇ $\mathrm{C}$ was investigated. Both total $\mathrm{Sb}$ and speciation analysis was carried out by ICP-MS and LC-ICP-MS, respectively. The $\mathrm{Sb}$ content was determined at the beginning of the experiment, after 7 and 15 days of storage.

\section{Total $\mathrm{Sb}$}

Total antimony concentrations throughout the experiment are plotted in Figure 7. Raki samples at the beginning of the test (day 0 ) showed significant concentrations of total Sb (0.5 - 3.9 $\left.\mu \mathrm{g} \mathrm{L}^{-1}\right)$. These values are comparable to those obtained in section 3.1 for the same samples. After a week of storage at $60^{\circ} \mathrm{C}$, raki samples showed a considerable increase in $\mathrm{Sb}$ concentration, exceeding the maximum level established by the EU for Sb in drinking waters. Sample R4 showed the highest concentration, reaching a value of $28 \mu \mathrm{g} \mathrm{L}^{-1}$. After 2 weeks of storage, $\mathrm{Sb}$ concentrations keep increasing sharply in samples $\mathrm{R} 1$ and $\mathrm{R} 4$ reaching values of 36 and $51 \mu \mathrm{g} \mathrm{L}^{-1}$, respectively, whereas in the rest of the samples this increase was not as pronounced, or even the values obtained were of the same order of magnitude as those obtained after 1 week.

\section{Sb speciation}

The analysis of $\mathrm{Sb}$ species in raki samples during the whole experiment are depicted in Figure 8. Concentrations of the organic complex of $\mathrm{Sb}$ were calculated by means of the external curve calibration of $\mathrm{Sb}(\mathrm{V})$ standards. At the beginning of the experiment, the predominant species was the proposed acetaldehyde-bisulphite pyruvate $\mathrm{Sb}$ complex in all the raki samples. However, after a week of storage, the concentration of this species decreased slightly or even disappeared as in the case of the R2 sample. $\mathrm{Sb}(\mathrm{V})$ concentration increased slightly in all samples $\left(0.2-2.1 \mu \mathrm{g} \mathrm{L}^{-1}\right)$ whereas that of $\mathrm{Sb}$ (III) increased sharply $\left(2.9-11.6 \mu \mathrm{g} \mathrm{L}^{-1}\right)$. After 2 weeks of storage, the presence of the organic complex of Sb kept decreasing and disappeared in samples $\mathrm{R} 1, \mathrm{R} 3$ and $\mathrm{R} 4$. $\mathrm{Sb}(\mathrm{V})$ concentration, with respect to the values obtained after 1 week of storage, increased slightly $\left(0.8-26 \mu \mathrm{g} \mathrm{L}^{-1}\right)$ whereas $\mathrm{Sb}$ (III) had no specific trend. Sample R4 showed the highest concentration of $\mathrm{Sb}$ (III), reaching a value of $22 \mu \mathrm{g} \mathrm{L^{-1 }}$.

This fact could be due to a simultaneous release of antimony from PET and a conversion of the Sb species. Raki samples contain high amounts of allyl alcohols and other organic substances which can stabilise or even complex the Sb released from PET, as demonstrated in section 3.2. However, the exposure at high temperature may decompose these complexes to their inorganic species, and simultaneously, more $\mathrm{Sb}$ (III) may be released from PET. As an example,

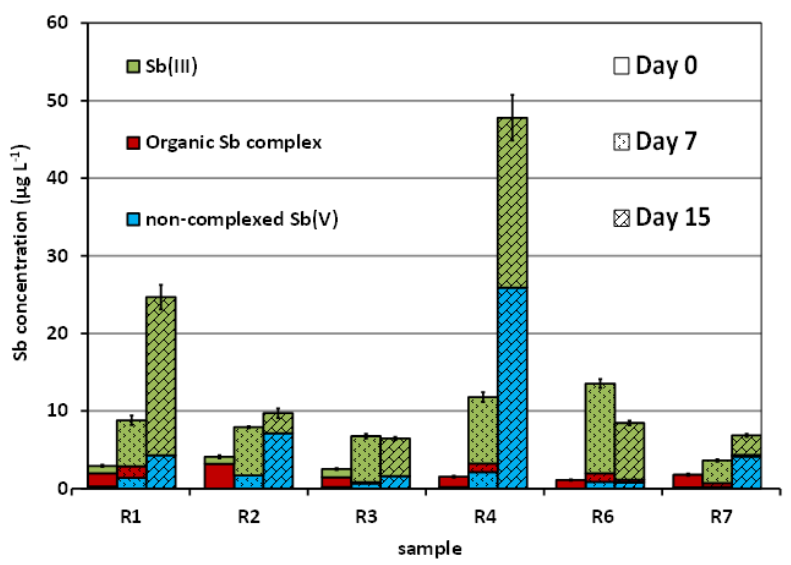

Figure 6. Evolution of $\mathrm{Sb}$ species concentrations in PET bottled raki stored at 60 으 for 15 days. 


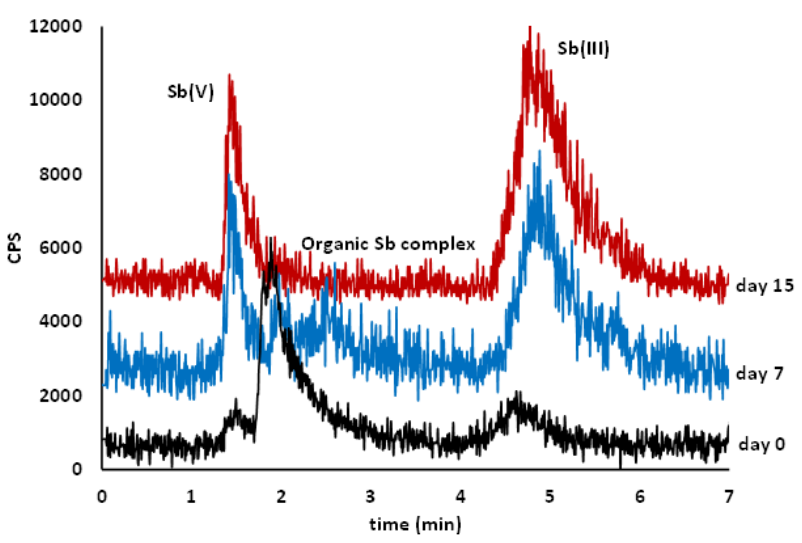

Figure 7. LC-ICP-MS chromatograms obtained for R1 at days 0,7 , and 15.

chromatograms obtained from the raki sample R1 are shown in Figure 9.

Table 2 summarises the total Sb concentration and the sum of the species obtained together with the recovery. As observed in section 3.2, good recoveries, from 70 to $110 \%$, were observed in some cases. However some low recoveries were also observed (down to 40\%). These facts demonstrate again that some other minor $\mathrm{Sb}$ species could be present in the raki samples but are not detected as they do not elute from the column.

These high $\mathrm{Sb}$ concentrations obtained in the migration experiment exceed the maximum limit of the total antimony in water $\left(5 \mu \mathrm{g} \mathrm{L}^{-1}\right)$ and are much higher than the Sb concentrations obtained in the high temperature migration studies previously published, ${ }^{19}$ in which concentrations up to $6 \mu \mathrm{g} \mathrm{L}^{-1}$ were reached at 15 days of storage in PET bottled waters. Moreover, the more toxic $\mathrm{Sb}$ (III) species predominant in some of the samples. Thus, it is recommended not to expose spirit beverages to elevated temperatures if they are stored in PET, as their matrix characteristics may easily promote Sb migration from PET.

\section{Conclusions}

Reliable and reproducible determination of $\mathrm{Sb}$ in spirit samples has been assessed by ICP-MS. Concentrations up to 4 $\mu \mathrm{g} \mathrm{L}^{-1}$ were found, which is close to the maximum limit established by the EU in drinking waters. The most suitable LC procedure for $\mathrm{Sb}$ species separation consisted of using as mobile EDTA $10 \mathrm{mmol} \mathrm{L}^{-1}$ at $\mathrm{pH} 4$ with $0.5 \%$ methanol. The predominant $\mathrm{Sb}$ species is an organic $\mathrm{Sb}$ complex. This complex was identified by LC-SSI- and ESI- MS, whose structural elucidation was established using HRMS. The proposed structure resulted in a complex with $\mathrm{m} / \mathrm{z} 474.89456$ and the molecular formula $\left[\mathrm{Sb}\left(\mathrm{C}_{2} \mathrm{H}_{5} \mathrm{O}_{4} \mathrm{~S}\right)_{2}\left(\mathrm{C}_{3} \mathrm{H}_{3} \mathrm{O}_{3}\right)(\mathrm{OH})\right]^{-}$, taking as ligands one molecule of pyruvic acid and two molecules of an acetaldehyde-bisulphite adduct.

According to the conducted migration studies, temperature and spirit matrix potentially affects Sb leaching from PET bottles, producing a rapid release in just one week of storage. Extremely high concentrations up to $51 \mu \mathrm{g} \mathrm{L}^{-1}$ were obtained. It is therefore highly recommended not to expose PET bottled beverages to elevated temperatures, as a rapid release of $\mathrm{Sb}$ has been demonstrated. The results obtained in this study could be used in the proposal of further Directives on $\mathrm{Sb}$ in other beverages other than from water.

Table 2. Total Sb concentration and sum of the species $\left(\mu \mathrm{g} \mathrm{L}^{-1}\right)$ together with the column recovery for PET bottled raki samples stored at $60^{\circ} \mathrm{C}$ for 15 days.

\begin{tabular}{|c|c|c|c|c|}
\hline Day & Sample & Total Sb & $\begin{array}{l}\text { Sum of } \\
\text { species }\end{array}$ & $\begin{array}{c}\text { Column } \\
\text { recovery } \\
(\%)\end{array}$ \\
\hline \multirow{6}{*}{0} & $\mathrm{R} 1$ & $3.91 \pm 0.28$ & $2.94 \pm 0.13$ & 75.3 \\
\hline & $\mathrm{R} 2$ & $3.73 \pm 0.12$ & $4.12 \pm 0.20$ & 110.4 \\
\hline & R3 & $3.64 \pm 0.16$ & $2.53 \pm 0.13$ & 69.5 \\
\hline & R4 & $1.45 \pm 0.09$ & $1.55 \pm 0.11$ & 107.5 \\
\hline & R6 & $0.52 \pm 0.02$ & $1.124 \pm 0.073$ & 216.5 \\
\hline & R7 & $0.66 \pm 0.04$ & $1.80 \pm 0.15$ & 272.4 \\
\hline \multirow{6}{*}{7} & R1 & $9.07 \pm 0.21$ & $8.81 \pm 0.62$ & 97.2 \\
\hline & $\mathrm{R} 2$ & $10.79 \pm 0.60$ & $7.92 \pm 0.12$ & 73.4 \\
\hline & R3 & $13.13 \pm 0.68$ & $6.77 \pm 0.28$ & 51.5 \\
\hline & R4 & $27.57 \pm 2.07$ & $11.79 \pm 0.62$ & 42.8 \\
\hline & R6 & $17.77 \pm 1.81$ & $13.54 \pm 0.57$ & 76.2 \\
\hline & R7 & $5.63 \pm 0.23$ & $3.63 \pm 0.17$ & 55.4 \\
\hline \multirow{6}{*}{15} & R1 & $36.16 \pm 0.65$ & $24.68 \pm 1.58$ & 68.3 \\
\hline & $\mathrm{R} 2$ & $13.37 \pm 1.56$ & $9.72 \pm 0.61$ & 59.4 \\
\hline & R3 & $15.83 \pm 1.35$ & $6.46 \pm 0.21$ & 40.8 \\
\hline & R4 & $50.85 \pm 2.09$ & $47.79 \pm 2.93$ & 94.0 \\
\hline & R6 & $10.36 \pm 1.09$ & $8.46 \pm 0.31$ & 81.7 \\
\hline & R7 & $9.92 \pm 0.71$ & $6.87 \pm 0.20$ & 69.3 \\
\hline
\end{tabular}

\section{Acknowledgements}

We thank Prof. A. Spiros for providing raki samples and CCiTUB for support with HRMS. We also thank the "Grup de Recerca Consolidat" (project number 2014 SGR 1277), the Research Vice Rectorate of the University of Barcelona and the "Ministerio de Economia y Competitividad" (Project CTQ2015-68685-R) for the financial help received to support this study. S. Carneado thanks the financial help provided by the Ministerio de Educación from Spain. Finally, the authors also acknowledge co-funding by the EU-European Regional Development Fund and the Greek Ministry of Education / EYAE-ETAK through program NSRF 2007-2013/EחAN II/Action "SYNERGASIA" (095YN-13-832).

\section{References}

1 R. Ashby, Food Addit. Contam., 1988, 5, 485-492.

2 S. M. Biros, B. M. Bridgewater, A. Villeges-Estrada, J.M. Tanski and G. Parkin, Inorg. Chem., 2002, 41, 4051-4057.

3 B. Duh, Polymer, 2002, 43, 3147-3154.

4 S. M. Aharoni, Polym. Eng. Sci., 1998, 38, 1039-1047.

5 R. Poon, I. Chu, P. Lacavalier, V. Valli, W. Foster, S. Gupta and B. Thomas, Food Chem. Toxicol., 1998, 36, 21-35.

6 R. E. Rivas, I. López-García and M. Hernández-Córdoba, Spectrochim. Acta, Part B, 2009, 64, 329-333.

7 Directive 2003/40/EC, http://eur-lex.europa.eu/legalcontent/EN/TXT/PDF/?uri= CELEX:32003L0040\&from=EN, (accessed December 2016). 
8 National Primary Drinking Water Regulations, http://water.epa.gov/drink/ contaminants/upload/mcl-2.pdf, (accessed December 2016).

9 W. Shotyk, M. Krachler and B. Chen, J. Environ. Monit., 2006, 8, 288-292.

10 W. Shotyk and M. Krachler, Environ. Sci. Technol., 2007, 41, 1560-1563.

11 Y. Takahashi, K. Sakuma, T. Itai, G. Zheng and S. Mitsunobu, Environ. Sci. Technol., 2008, 42, 9045-9050.

12 P. Westerhoff, P. Prapaipong, E. Shock and A. Hillaireau, Water Res., 2008, 42, 551-556.

13 S. Keresztes, E. Tatár, V. G. Mihucz, I. Virág, C. Majdik and G. Záray, Sci. Total Environ., 2009, 407, 4731-4735.

14 F. Welle and R. Franz, Food Addit. Contam., 2011, 28, 115126.

15 A. Tukur, L. Sharp, B. Stern, C. Tizaoui and H. Benkreira, J. Environ. Monit., 2012, 14, 1237-1247.

16 L. Hureiki and Y. Mouneimne, Water Sci. Technol.: Water Supply, 2012, 12:2, 193-199.

17 S. Rungchang, S. Numthuam, X. Qiu, Y. Li and T. Satake, J. Food Eng., 2013, 115, 322-329.

18 J. Brandao, M. Moyo and J. Okonkwo, Water Sci. Technol.: Water Supply, 2014, 14:2, 181-188.

19 S. Carneado, E. Hernández-Nataren, J. F. López-Sánchez and A. Sahuquillo, Food Chem., 2015, 166, 544-550.

20 A. Gueven, J. Inst. Brew., 2013, 119, 126-132.

21 R. E. Anli and M. Bayram, Food Rev. Int., 2010, 26, 246-269.

22 C. Bach, X. Dauchy, M. C. Chagnon and S. Etienne, Water Res. 2012, 46, 571-583.

23 M. M. Antonakis, A. Tsirigotaki, K. Kanaki, C. J. Milios and S. A. Pergantis, J. Am. Soc. Mass Spectrom., 2013, 24:8, 12501259.

24 F. Weigend and R. Ahlrichs, Phys. Chem. Chem. Phys., 2005, 7 3297-3305.

25 F. Weigend and M. Häser, Theor. Chem. Acc., 1997, 97, 331340.

26 R. Ahlrichs, M. Bar, M. Haser, H. Horn and C. Kolmel, Chem. Phys. Lett., 1989, 162, 165-169.

27 Directive 97/48/EC, http://eur-lex.europa.eu/legalcontent/EN/TXT/PDF/?uri= CELEX:31997L0048\&from=en, (accessed December 2016).

28 H. R. Hansen and S. A. Pergantis, Anal. Chem., 2007, 79, 53045311.

29 A. García-Ruiz, T. Requena, C. Peláez, B. Bartolomé, M. V. Moreno-Arribas and M. C. Martínez-Cuesta, Food Control, 2013, 32, 477-483.

30 R. M. Ramos, L. M. Gonçalves, V. Vyskočil and J. A. Rodrigues, Electrochem. Commun., 2016, 63, 52-55.

31 J. C. Danielwicz, Am. J. Enol. Vitic., 2007, 58, 53-60.

32 D. P. Kjell, B. J. Slattery, M. J. Semo, J. Org. Chem., 1999, 64 5722-5724.

33 B. C. Rankine, J. Sci. Fd. Agric., 1965, 16, 394-398. 